\title{
Identifikasi Risiko Rantai Pasok dengan Metode House of Risk (HOR)
}

\author{
Juniardo Akmal Hadi ${ }^{1}$, Melinska Ayu Febrianti², Gisya Amanda Yudhistira ${ }^{3}$, Qurtubi ${ }^{4 *}$ \\ 1,2,3,4 Jurusan Teknik Industri, Fakultas Teknologi Industri, Universitas Islam Indonesia \\ Email: 16522040@students.uii.ac.id; 18522320@students.uii.ac.id; 18522318@students.uii.ac.id; \\ "qurtubi@uii.ac.id
}

DOI: 10.20961/performa.19.2.46388

\begin{abstract}
Abstrak
Zaman modern yang selalu berkembang berdampak pada industri manufaktur. Berkaitan dengan teknologi untuk mengubah barang mentah menjadi barang jadi. Melihat persaingan yang ketat dan kompetitif antar perusahaan yang dituntut untuk memenuhi permintaan pelanggan. PT XYZ merupakan perusahaan yang bergerak pada bidang tekstil. Permintaan kain yang selalu dinamis menimbulkan dampak inventory yang melimpah dan waktu tunggu pengiriman bahan baku yang tidak pasti membuat perusahaan sulit memenuhi semua permintaan. Identifikasi risiko dilakukan dengan metode Failure Mode and Effect Analysis (FMEA), menilai pentingnya keefektifitasan proses bisnis dalam implikasi risiko yang terjadi. Kemudian, pendekatan House of Risk (HOR) dapat dilakukan analisis terhadap potensi risiko pada perusahaan saat melakukan produksi dan melihat tingkat probabilitas risiko serta dampak yang terjadi dan berdampak pada pengambilan keputusan agar tidak merugikan. Hasil dari penelitian ini menunjukkan bahwa terdapat 5 risk event dan 28 risk agent yang menjadi risiko rantai pasok serta rekomendasi guna menanggulangi pada agen risiko prioritas.
\end{abstract}

Kata kunci: FMEA, house of risk, manajemen rantai pasok, manajemen risiko, SCOR

\begin{abstract}
Modern era has an impact on the manufacturing industry. Relate to technology to turn raw goods into finished goods. Look at competitive in competition between companies that are required to customer demand. PT XYZ is a textile company. The dynamic demand for fabrics has the impact of abundant inventory and uncertain raw material delivery waiting times make it difficult for the company to meet all demand. Risk identification using Failure Mode and Effect Analysis (FMEA) method, assessing the importance of the effectiveness business processes in the risk implications that occur. Then, the House of Risk (HOR) approach can be analyzed against potential risks in the company when conducting production and look at the degree of probability risk as well as the impact that occurs and impacts decision making so as not to be detrimental. The results of this study show that there are 5 risk events and 28 risk agents that become supply chain risks as well as recommendations to the priority risk agents.
\end{abstract}

Keywords: FMEA, house of risk, risk management, supply chain management, SCOR

\section{Pendahuluan}

Perkembangan zaman menuju era industri berdampak pada proses industri manufaktur. Perusahaan pada produksi barang mentah menjadi barang jadi. Teknologi yang berdampak pada kegiatan keseharian akan menjadikan menjadi faktor efisien dan efektivitas dalam seluruh elemen kegiatan. Berdampak pada implikasi sebuah perusahaan, memenuhi seluruh demand pelanggan. Perusahaan diwajibkan untuk memperhatikan alur produksi yang efektif dan efisien serta fasilitas penunjang lainnya agar sesuai dengan keinginan pelanggan dengan tujuan menjadikan output yang baik dan tepat waktu (Badariah et al., 2013).

Persediaan yang baik harus dimiliki oleh seluruh perusahaan, dengan perubahan jumlah permintaan terhadap produk pada perusahaan dan pula mengubah kebijakan yang ada, diberikan contoh pada tingkat pemesanan kembali (Hayati, 2015). Dalam praktiknya perusahaan harus mempertahankan hubungan jangka panjang seperti berhubungan dengan pemasok, pelanggan,

*Corresponding author 
distributor sebagai tujuan mempertahankan preferensi bisnis dalam konteks jangka panjang (Listyawati, 2013).

Strategi yang digunakan untuk mengelola perusahaan sangat tepat menggunakan manajemen rantai pasok, namun dalam perjalanan proses pekerjaannya melibatkan seluruh elemen, baik pihak internal atau perusahaan dengan pihak eksternal di mana perusahaan yang mengatur dengan seluruh proses kegiatan bisnis pada perusahaan (Tampubolon et al., 2013). Terlihat bahwa tingkat kompleksitas yang menggabungkan banyak elemen akan memunculkan risiko yang dapat membuat dampak pada perusahaan. Baik dampak positif maupun negatif pada permintaan pelanggan dan biaya bisnis pada perusahaan. Seluruh kegiatan dalam proses perusahaan meliputi aliran material, aliran kegiatan, dan aliran finansial pada rantai pasok yang disebut bagian kegiatan dari manajemen rantai pasok (Kusnindah, Sumantri, \& Yuniarti, 2014), sehingga perlu adanya identifikasi dan pengelolaan terhadap risiko yang berdampak pada perusahaan. Menurut (Rosih, Choiri, \& Yuniarti, 2015) Setiap proses yang ada pada perusahaan memiliki risiko. Identifikasi adanya indikator risiko berupa masalah, kebijakan dan perubahan politik, penambahan demand serta penambahan layanan bisnis. Pertimbangan dari banyaknya hal tersebut dapat menimbulkan risiko di masa mendatang.

PT XYZ adalah perusahaan pada bidang tekstil dengan memproduksi kain grey dan kain mori. Permintaan kain yang selalu dinamis menimbulkan dampak inventory yang melimpah dan waktu tunggu pengiriman bahan baku yang tidak pasti membuat perusahaan sulit memenuhi semua permintaan. Maka, melalui identifikasi manajemen risiko terhadap risiko-risiko yang terlibat, sehingga dapat mengurangi dampak dari kerugian yang akan terjadi masih dalam konteks dapat diterima yang merugikan bagi pencapaian dari tujuan fungsi dan strategi organisasi maupun perusahaan (Norken, Astana, \& Manuasri, 2012). Manajemen risiko melibatkan identifikasi bahaya apa saja yang terlibat, menentukan kegagalan dalam sistem yang dapat menyebabkan bahaya atau risiko, memprioritaskan bahaya yang memiliki potensi yang tinggi dalam penanganannya. Ketidakpastian dalam ketersediaan kain adalah permintaan produk yang bersifat tidak pasti untuk berbagai variasi inovasi bentuk kain yang tersedia dalam inventori dan jumlahnya yang terbatas. Padahal ketersediaan bahan baku yaitu kapas juga bersifat tidak pasti dan waktu tunggu pemesanan barang baku yang terbilang lama.

Dengan demikian, diperlukan identifikasi dan analisis risiko untuk diketahui bentuk perbaikannya. Risiko yang ditimbulkan akibat segala proses aktivitas bisnis. dapat berdampak baik atau sebaiknya, mengganggu proses bisnis hingga kerugian yang didapat. Penting untuk mengetahui risiko yang terjadi guna melihat peluang untuk pengambilan keputusan karena berdampak pada aktivitas yang akan dilakukan selanjutnya. Sehingga, dapat diberikan rekomendasi atas perbaikan untuk pengukuran sistem kerja sebelumnya. Identifikasi risiko dilakukan melalui metode Failure Mode and Effect Analysis (FMEA). Kemudian, dengan pendekatan House of Risk (HOR) dapat dilakukan analisis terhadap potensi risiko pada perusahaan saat melakukan produksi dan melihat tingkat probabilitas risiko serta dampak yang terjadi. Sehingga dapat mengurangi probabilitas munculnya risiko yang berdampak negatif serta memberikan usulan tindakan pencegahan dari agen risiko. Melihat pada dampak risiko serta pemberian rekomendasi untuk mengurangi dampak dari probabilitas penyebab kegagalan yang terjadi. Akan dapat mengurangi probabilitas munculnya risiko yang berdampak negatif serta memberikan usulan tindakan pencegahan dari agen risiko. Melihat pada dampak risiko serta pemberian rekomendasi untuk mengurangi dampak dari probabilitas penyebab kegagalan yang terjadi. Efek berkelanjutnya ketika sebuah perusahaan dapat mengurangi risiko-risko yang terjasi sehingga dapat meminimalisis kegagalan yang menyebabkan kerugian dan dampak cost yang tinggi sehingga menimbulkan kerugian dari sisi material, manusia, mesin dan metode. Adapun untuk meningkatkan produktivitas yang diukur dari output yang dihasilkan melebihi dari input. Hal ini kemudian dapat membawa deman pelanggan yang tidak terjadi penumpukan inventory atau terlambatnya penyampaian produk kepada pelanggan. Dapat dikatakan aliran dari proses perusahaan lancar dari perusahaan hingga tangan pelanggan. 


\section{Metode Penelitian}

Bagian PT XYZ, selanjutnya disebut perusahaan, bergerak pada bidang manufaktur yaitu pada pembuatan kain yang akan didistribusikan dan biasanya digunakan untuk bahan seragam atau lainnya. Penelitian bertujuan mengetahui faktor-faktor risiko apa saja yang terkait jika dilakukan produksi dan nilai terbesar di dalam rantai pasok pada perusahaan dalam mengidentifikasi risiko-risiko yang terjadi.

\section{a. Pemetaan Aktivitas SCM}

Pemetaan Aktivitas SCM dilakukan dengan menggunakan metode SCOR. Pemetaan ini dilakukan dengan tujuan mengidentifikasi aktivitas dari pemasok hingga ke konsumen akhir. Penggunaan metode ini dalam merancang pengukuran kinerja supply chain pada proses yang dilakukan, membuat perusahaan dapat melakukan evaluasi kinerja rantai pasok sehingga dari hasil evaluasi dapat dilakukan pemantauan, serta dapat mengetahui potensi risiko dari aktivitasaktivitas yang dilakukan kelompok pemasok hingga konsumen.

\section{b. Identifikasi Risiko}

Tahapan awal untuk identifikasi masalah secara mendasar dilakukan dengan observasi secara langsung di perusahaan. Menurut Widianto (2012) bahwa Supply Chain Management adalah suatu pendekatan secara keseluruhan pada proses manajemen material, seperti pada menyediakan, memproduksi, dan mendistribusikan produk kepada konsumen. Identifikasi risiko dengan metode Failure Mode and Effects Analysis (FMEA) berfokus pada 2 variabel, yaitu kemungkinan risiko terjadi (occurrence) dan dampak risiko (severity). Dalam menentukan tingkat kerusakan (severity), dapat ditentukan seberapa serius kerusakan yang dihasilkan. Nilai rangking severity di antara 1 sampai 10, di mana skala 1 menunjukkan tidak ada dampak dan skala 10 menunjukkan dampak bahaya. Dalam menentukan occurrence dapat ditentukan seberapa banyak gangguan yang dapat menyababkan risiko. Nilai occurrence antara 1 sampai 10, yang dimana nilai skala 1 menunjukan hampir risiko tersebut tidak pernah terjadi dan skala 10 menunjukan risiko tersebut hampir pasti terjadi (Shahin,2004). Pengumpulan data pada identifikasi risiko dilakukan dengan wawancara secara mendalam terhadap expert yang berpengalaman pada bidang bersangkutan. Terdiri dari 3 expert, yaitu petani yang berpengalaman kerja 9 tahun, pemasok yang bekerja sama selama 2 tahun, serta pekerja pengadaan bahan baku yang berpengalaman kerja 5 tahun.

\section{c. Perhitungan Risiko}

Tujuan House of Risk (HOR), yaitu untuk mengidentifikasi risiko dan melakukan desain mitigasi risiko yang berdasarkan hasil perhitungan risk assessment untuk mengurangi probabilitas risk agent yang terjadi melalui upaya pencegahan sesuai dengan tingkat prioritas risk agent. Tahapan manajemen HOR dibagi menjadi 2 fase, yaitu mengidentifikasi risiko dan penanganan risiko setelah melakukan identifikasi risiko. HOR fase 1 berfungsi pada penentuan sumber dari risiko yang berprioritas untuk dilakukan tindakan terhadap pencegahan dan HOR fase 2 berfungsi memberikan tindakan khusus atas pertimbangan pada sumber daya dengan pemilihan cost yang efektif (Trenggonowati, 2017).

HOR fase 1 untuk menentukan penilaian severity dan occurrence serta korelasi dari risk event dan risk agent, didapatkan dari hasil observasi langsung melalui wawancara terhadap pihak terkait. Kemudian, melakukan evaluasi hasil pengolahan data dan melakukan tahap selanjutnya, yakni HOR pada fase 2 dilakukan identifikasi lanjut pada agen risiko prioritas yang akan diberikan aksi mitigasi, berfungsi untuk meminimalisir dampak agen risiko tersebut.

\section{Hasil dan Pembahasan}

\subsection{Supply Chain Management}

Terdapat empat variabel yang terlibat di dalam rantai pasok perusahaan yaitu petani, pemasok, perusahaan, dan pelanggan. Berawal dari petani kapas yang hasil produksinya berupa 
tumbuhan kapas menjadi bahan baku utama dari kain. Kemudian pemasok mengolah kapas menjadi benang sebagai produknya, kemudian dikirim ke perusahaan yang mengolah benang menjadi kain. Pelanggannya adalah perusahaan-perusahaan yang mengolah kain menjadi baju dan celana fashion yang siap diperjualbelikan. Dilakukan pemetaan aktivitas supply chain perusahaan dengan menggunakan metode SCOR. Pemetaan ini dilakukan dengan tujuan untuk mengidentifikasi aktivitas dari pemasok hingga ke konsumen akhir. Penggunaan metode ini dalam perancangan pengukuran kinerja rantai pasok berdasarkan proses yang dilakukan, membuat perusahaan dapat melakukan evaluasi kinerja rantai pasok. Dengan demikian, hasil evaluasi dapat dilakukan monitoring serta dapat diketahui potensi risiko yang akan muncul dari aktivitas yang dilakukan kelompok pemasok sampai dengan konsumen. Pemetaan aktivitas rantai pasok pada perusahaan terdapat pada Tabel 1 .

Tabel 1. Pemetaan aktivitas metode SCOR perusahaan (Sumber: Hadi, 2019)

\begin{tabular}{|c|c|}
\hline Proses & Aktivitas \\
\hline Plan & Perencanaan dan pengendalian produksi \\
\hline \multirow[t]{3}{*}{ Source } & Pembelian bahan baku \\
\hline & Pemeriksaan bahan baku di laboratorium \\
\hline & Meletakkan bahan baku ke warehouse área \\
\hline \multirow[t]{4}{*}{ Make } & Proses produksi \\
\hline & Quality control \\
\hline & Packaging hasil produksi \\
\hline & Memindahkan barang jadi ke warehouse \\
\hline Deliver & Stock opname informasi ketersediaan barang jadi \\
\hline & Pengiriman produk ke pelanggan \\
\hline Return & Penanganan produk yang dikembalikan oleh pelanggan \\
\hline
\end{tabular}

\subsection{Identifikasi Risiko}

Identifikasi risiko dilakukan dengan metode Failure Mode Effects Analysis (FMEA). Terdapat dua variabel yang digunakan, yaitu kemungkinan terjadinya risiko (occurrence) dan dampak risiko (severity). Dari hasil kuesioner menyatakan bahwa kejadian risiko (risk event) yang terjadi pada rantai pasok kain sebanyak 5 kejadian risiko. Risk event perusahaan terdapat pada Tabel 2.

Tabel 2. Risk Event pada perusahaan (Sumber: Hadi, 2019)

\begin{tabular}{clccc}
\hline Code & \multicolumn{1}{c}{ Risk Event } & \multicolumn{3}{c}{ Severity } \\
& & Petani & Pemasok & Manufaktur \\
\hline E1 & Tingkat produktivitas menurun & 8 & 3 & 8 \\
E2 & Tidak memenuhi target kuantitas & 8 & 3 & 9 \\
E3 & Penumpukan inventory & 2 & 7 & 5 \\
E4 & Kerusakan mesin & 1 & 1 & 9 \\
E5 & Produk cacat & 7 & 7 & 9 \\
\hline
\end{tabular}

Perhitungan dari hasil pembobotan menunjukkan nilai severity untuk setiap kejadian risiko yang didapatkan melalui hasil wawancara expert. Kemudian dari hasil kuesioner selanjutnya dapat diidentifikasi bahwa risk agent rantai pasok perusahaan sebanyak 28 risk agent dengan nilai occurrence sesuai tingkat pekerjaan para expert. Risk Agent perusahaan terdapat pada Tabel 3.

Tabel 3. Risk Agent pada perusahaan (Sumber: Hadi, 2019)

\begin{tabular}{clc}
\hline Code & \multicolumn{1}{c}{ Risk Agent } & Occurance \\
\hline A1 & Karyawan yang tidak bekerja sesuai SOP & 6 \\
A2 & Pengiriman bahan baku yang telat & 4 \\
A3 & Sisir ekspansi rusak & 3
\end{tabular}




\begin{tabular}{clc}
\hline Code & \multicolumn{1}{c}{ Risk Agent } & Occurance \\
\hline A4 & Kualitas bahan baku yang kurang baik & 4 \\
A5 & Terlalu lama proses inspeksi & 6 \\
A6 & Karyawan kurang disiplin & 7 \\
A7 & Kerusakan pada mesin tunggal & 2 \\
A8 & Tidak adanya divisi pelatihan pada karyawan baru & 8 \\
A9 & kurang disiplinnya pengecekan mesin & 6 \\
A10 & Hari libur, bulan puasa & 5 \\
A11 & Penumpukan barang yang terlalu lama & 7 \\
A12 & Job desc yang tidak sesuai & 7 \\
A13 & Tidak menerapkan 5S & 8 \\
A14 & Kecelakaan kerja pada operator & 3 \\
A15 & Kesalahan pemberian inventaris barang & 3 \\
A16 & Target produksi yang terlalu tinggi & 5 \\
A17 & Kelalaian tenaga kerja & 5 \\
A18 & Permintaan yang dinamis & 5 \\
A19 & Kurang komunikasi antar pekerja & 5 \\
A20 & Kesalahan input data & 5 \\
A21 & Pemasok tidak dapat memenuhi kontrak dengan perusahaan & 5 \\
A22 & Proses pemeriksaan tidak sempurna & 5 \\
A23 & Kesalahan setup dan setting mesin & 5 \\
A24 & Variasi produk yang tinggi & 5 \\
A25 & Kondisi lingkungan kerja pada proses distribusi berjalan (hujan,dll) & 6 \\
A26 & Gagal panen & 5 \\
A27 & Cuaca ekstrem & 5 \\
A28 & Kurangnya perawatan terhadap tanaman & 5 \\
\hline & & 5 \\
\hline
\end{tabular}

\subsection{House of Risk Fase 1}

Dari hasil identifikasi menunjukkan terdapat 5 risk event dan 28 risk agent. Pada penelitian ini, kategori nilai severity yang didapat terdiri dari 3 tingkat stakeholder yaitu petani, pemasok, dan perusahaan. Penilaian severity yang dilakukan untuk setiap tingkat dikarenakan dampak dari suatu risiko yang terjadi tidak semuanya sama untuk setiap tingkat. Oleh karena itu hasil dari pengolahan HOR fase 1 dapat menghasilkan 3 jenis score Aggregrate Risk Priority (ARP). ARP diperoleh melalui hasil perkalian probabilitas sumber risiko (occurrence) dengan dampak kerusakan (severity) yang disebabkan oleh risiko tersebut. ARP berfungsi untuk menentukan prioritas risk agent untuk diidentifikasi dan dilakukan perancangan pada strategi mitigasi. Pada akhirnya tiga nilai ARP tersebut akan digabungkan untuk mengetahui total score ARP yang didapat. Pengolahan data HOR fase 1 disajikan pada Gambar 1.

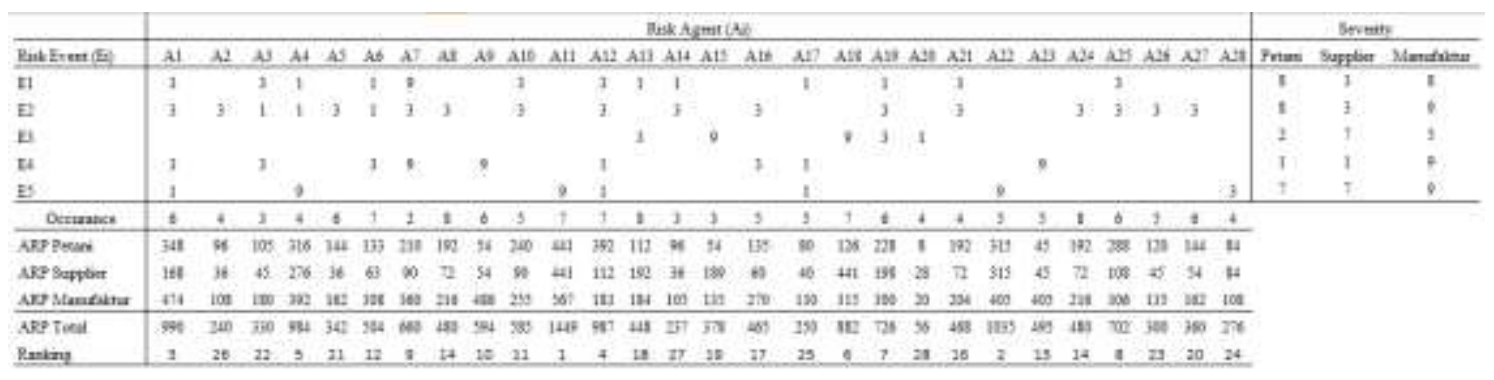

Gambar 1. Perhitungan House of Risk Fase 1 (Sumber: Hadi, 2019) 
Keterangan:

$\mathrm{Ai} \quad=$ Risk Agent

$\mathrm{Ei} \quad=$ Risk Event

ARP $=$ Aggregate Risk Priority

Rank $=$ Ranking prioritas risiko

Setelah didapatkan nilai ARP pada setiap risk agent, tahap selanjutnya yaitu mengurutkan agen-agen risiko yang memiliki persentase terjadi risiko tertinggi ke terendah. Menentukan agen risiko berdasarkan hukum pareto. Berdasarkan hukum pareto menjelakan bahwa $80 \%$ dari permasalahan yang disebabkan dan $20 \%$ untuk risiko kritis. Penjelasan dalam hal penanggulangan terhadap 20\% dari risiko tersebut, pada $80 \%$ lainnya merupakan dampak risiko perusahaan yang dapat diminimalisir ataupun diatasi. Persentase $20 \%$ masuk pada kode A1 dengan perhitungan kumulatif sampai $22,12 \%$. Berarti kode A1 termasuk ke dalam agen risiko yang harus diidentifikasi dan ditanggulangi. Perhitungan pareto agen risiko pada Tabel 4. dan diagram pareto agen risiko pada Gambar 2.

Tabel 4. Perhitungan Pareto Agen Risiko (Sumber: Hadi, 2019)

\begin{tabular}{ccccc}
\hline Code & Nilai ARP & Persentase & Kumulatif & Kategori \\
\hline A11 & 1449 & $9.23 \%$ & $9.23 \%$ & Prioritas \\
A22 & 1035 & $6.59 \%$ & $15.82 \%$ & \\
A1 & 990 & $6.30 \%$ & $22.12 \%$ & \\
A12 & 987 & $6.29 \%$ & $28.41 \%$ & Non Prioritas \\
A4 & 984 & $6.27 \%$ & $34.67 \%$ & \\
A18 & 882 & $5.62 \%$ & $40.29 \%$ & \\
A19 & 726 & $4.62 \%$ & $44.91 \%$ & \\
A25 & 702 & $4.47 \%$ & $49.39 \%$ & \\
A7 & 660 & $4.20 \%$ & $53.59 \%$ & \\
A9 & 594 & $3.78 \%$ & $57.37 \%$ & \\
A10 & 585 & $3.73 \%$ & $61.10 \%$ & \\
A6 & 504 & $3.21 \%$ & $64.31 \%$ & \\
A23 & 495 & $3.15 \%$ & $67.46 \%$ & \\
A8 & 480 & $3.06 \%$ & $70.52 \%$ & \\
A21 & 468 & $2.98 \%$ & $76.55 \%$ & \\
A16 & 465 & $2.96 \%$ & $79.51 \%$ & \\
A13 & 448 & $2.85 \%$ & $82.37 \%$ & \\
A15 & 378 & $2.41 \%$ & $84.77 \%$ & \\
A27 & 360 & $2.29 \%$ & $87.07 \%$ & \\
A5 & 342 & $2.18 \%$ & $89.24 \%$ & \\
A3 & 330 & $2.10 \%$ & $91.35 \%$ & \\
A26 & 300 & $1.91 \%$ & $93.26 \%$ & \\
A28 & 276 & $1.76 \%$ & $95.01 \%$ & \\
A17 & 250 & $1.59 \%$ & $96.61 \%$ & \\
A2 & 240 & $1.53 \%$ & $98.13 \%$ & \\
A14 & 237 & $1.51 \%$ & $99.64 \%$ & \\
A20 & 56 & $0.36 \%$ & $100 \%$ & \\
\hline Total & 15703 & $100 \%$ & $100 \%$ & \\
\hline & & & & \\
\end{tabular}




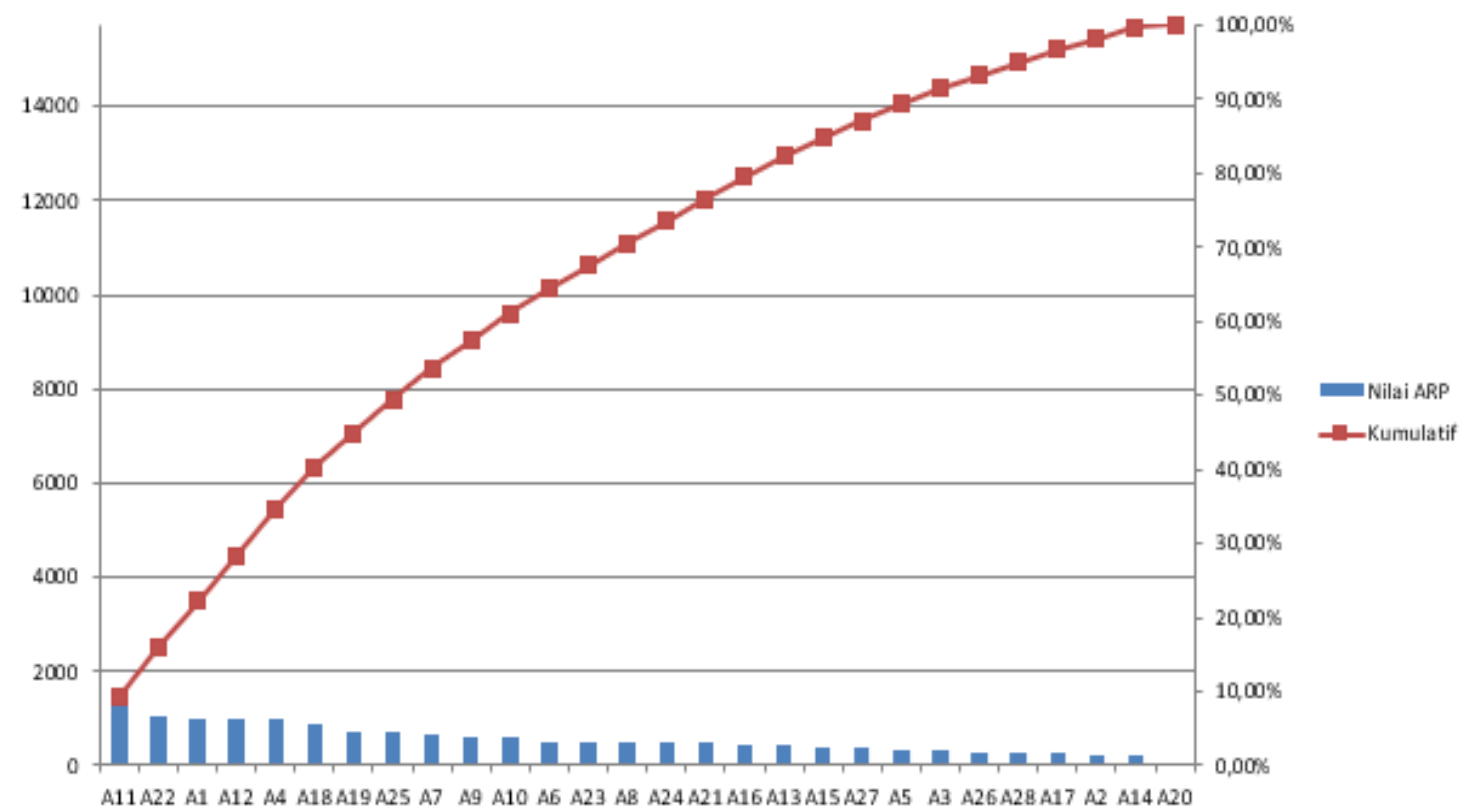

Gambar 2. Diagram Pareto Agen Risiko (Sumber: Hadi, 2019)

\subsection{House of Risk Fase 2}

Analisis House of Risk pada Fase 2 adalah tahap pada evaluasi pada agen risiko prioritas guna memberikan aksi mitigasi agar dapat meminimalisir dampak dari agen risiko tersebut. Langkah pertama yaitu identifikasi aksi mitigasi untuk mencapai tingkat ideal sehingga dapat menanggulangi agen risiko utama. Aksi mitigasi untuk menanggulangi setiap agen risiko pada Tabel 5.

Tabel 5. Aksi Mitigasi (Sumber: Hadi, 2019)

\begin{tabular}{ll}
\hline \multicolumn{1}{c}{ Agen Risiko } & \multicolumn{1}{c}{ Aksi Mitigasi } \\
\hline Penumpukan barang yang terlalu lama & Peningkatan informasi sistem (PA-1) \\
& Evaluasi kinerja dengan pelanggan (PA-2) \\
Proses inspeksi yang tidak sempurna & Melakukan training pada karyawan (PA-3) \\
& Peningkatan teknologi pada mesin inspeksi repair (PA-4) \\
Karyawan yang tidak bekerja sesuai SOP & Pemberian sanksi pada pekerja yang bekerja tidak sesuai SOP (PA-5)
\end{tabular}

Setelah melakukan identifikasi aksi mitigasi, melakukan pengukuran dari nilai korelasi (Ejk) antara agen risiko utama dengan aksi mitigasi. Pemberian nilai korelasi dengan skala yang sama pada nilai korelasi antara segen risiko dengan kejadian risiko. Bilangan tersebut yaitu 0,1,3, dan 9. Selanjutnya, dilakukan pengukuran derajat kesulitan (Dk) yang di mana untuk gambaran dari kategori untuk tingkatan kesulitan pada aksi mitigasi tersebut. Bobot score untuk tingkat kesulitan pada Tabel 6.

Tabel 6. Skala Nilai Mitigasi (Sumber: Hadi, 2019)

\begin{tabular}{cl}
\hline Bobot & \multicolumn{1}{c}{ Keterangan } \\
\hline 3 & Aksi mitigasi dapat dengan mudah diterapkan \\
4 & Aksi mitigasi sedikit sulit diterapkan \\
5 & Aksi mitigasi sulit untuk diterapkan \\
\hline
\end{tabular}

Langkah berikutnya, melakukan perhitungan total keefektifan (TEk) dengan menjumlahkan hasil perkalian antara nilai korelasi (Ejk) dengan ARP pada masing-masing agen risiko prioritas 
(Aj). Kemudian, menghitung total keefektifan (TEk) melalui cara menjumlahkan hasil dari perkalian nilai korelasi (Ejk) dengan ARP setiap agan risiko prioritas (Aj). Kemudian, penilaian terhadap effectiveness to difficulty ratio (ETD) dengan cara membagi nilai (Tek) dengan derajat kesulitas (Dk). Hasil nilai ETD akan dijadikan sebagai parameter aksi mitigasi berdasarkan dari kemudahan untuk melaksanakannya. Dapat dikatakan nilai ETD yang semakin tinggi diartikan semakin ideal aksi mitigasi untuk diaplikasikannya. Rekapitulasi perhitungan HOR Fase 2 pada Tabel 7.

Tabel 7. Perhitungan HOR Fase 2 (Sumber: Hadi, 2019)

\begin{tabular}{cccccccc}
\hline To be Treated Risk Agent (Aj) & \multicolumn{7}{c}{ Preventive Action (P ak) } \\
& & PA-1 & PA-2 & PA-3 & PA-4 & PA-5 & ARP \\
\hline Penumpukan barang yang terlalu lama & A11 & 9 & 9 & & & 1449 \\
Proses inspeksi yang tidak sempurna & A22 & & & 9 & 3 & 1035 \\
Karyawan yang tidak bekerja sesuai SOP & A1 & & & & & 9 & 990 \\
Total effectiveness of action - $k$ & & 13041 & 13041 & 9315 & 3105 & 8910 \\
Degree of difficulty performing action & $-k$ & 3 & 4 & 4 & 5 & 4 \\
Effectiveness difficulty ratio & 4347 & 3260.25 & 2328.75 & 621 & 2227.5 \\
Rank of priority & 1 & 2 & 3 & 5 & 4 \\
\hline
\end{tabular}

Berdasarkan hasil perhitungan HOR fase 2, disimpulkan bahwa pembuatan prosedur aktivitas peningkatan sistem informasi pelanggan (PA-1) merupakan aksi mitigasi yang paling ideal. Pengurutan aksi mitigasi dari nilai ETD yang terbesar hingga nilai ETD yang terkecil. Arti dari nilai ETD yang lebih tinggi dapat dengan mudah diterapkan dibandingkan dengan nilai ETD yang lebih rendah.

\subsection{Rekomendasi Aksi Mitigasi}

Berdasarkan hasil analisis maka didapatkan rekomendasi aksi mitigasi yang dapat dilakukan oleh perusahaan.

\section{a. Peningkatan informasi sistem (PA-1)}

Sistem pengendalian internal melalui peningkatan informasi antar divisi dapat mengurangi penumpukan inventory. Salah satu kegiatan yang dapat meningkatkan peningkatan informasi internal adalah stock opname secara berkala, sehingga dapat mendapatkan informasi yang lebih akurat tentang inventory.

\section{b. Evaluasi kinerja dengan pelanggan (PA-2)}

Jika sistem kontrak dengan pelanggan belum berjalan sesuai rencana, maka perusahaan dapat mengevaluasi kontrak dengan pelanggan untuk mendapatkan sistem kontrak yang baru sehingga dapat mencegah masalah penumpukan inventory produk akhir.

\section{c. Melakukan training pada karyawan (PA-3)}

Tujuan dari training adalah memberikan pemahaman serta pengetahuan pekerjaan yang ditugaskan pada aktivitasnya guna menghindari kesalahan semaksimal mungkin. Sehingga, membuat efektif, efisien dan meningkatkan produktivitas.

\section{d. Peningkatan teknologi pada mesin inspeksi repair (PA-4)}

Peningkatan teknologi pada mesin inspeksi repair akan dapat meminimalisir kesalahan operator, sehingga mengurangi kesalahan-kesalahan operator ketika melakukan inspeksi pada kain.

\section{e. Pemberian sanksi pada pekerja yang bekerja tidak sesuai SOP (PA-5)}

Pemberian sanksi pada pekerja akan dapat mengurangi pekerja yang bekerja tidak sesuai SOP. Sehingga dapat mengurangi timbulnya risiko yang berdampak pada perusahaan maupun pekerja. 


\section{Simpulan}

Dari hasil wawancara expert didapatkan adanya lima risk event dan 28 risk agent yang menjadi risiko-risiko pada rantai pasok dari perusahaan. Kemudian, dari hasil perhitungan House of Risk (HOR) fase 1 didapatkan tiga risk agent dengan nilai ARP tertinggi yaitu penumpukan barang yang terlalu lama (A11), proses inspeksi yang tidak sempurna (A22), dan karyawan yang bekerja tidak sesuai SOP (A1), serta menyumbangkan persentase kumulatif mencapai 22,12\%.

Rekomendasi dari aksi mitigasi dalam menanggulangi agen-agen risiko prioritas antara lain, peningkatan informasi sistem, evaluasi kinerja dengan pelanggan, melakukan training pada karyawan, peningkatan teknologi pada mesin inspeksi repair dan pemberian sanksi pada pekerja yang bekerja tidak sesuai SOP.

Implementasi dari penelitian ini dapat digunakan sebagai perbandingan dengan objek lain seperti departemen internal perusahaan agar lebih rinci atau proses bisnis perusahaan lainnya guna melihat keefektifitasan dalam menangani suatu masalah yang berdampak menjadi risiko. Sehingga, diharapkan dapat mengurangi dampak risiko dan penyumbang kegagalan atau kerugian dalam perusahaan. Ditujukan untuk produktivitas perusahaan, dimana ketika output yang dihasilkan melebihi dari input yang ada. Karena terdapat manajemen dari risiko serta rekomendasi yang diberikan untuk menanggulangi hal yang merugikan bagi perusahaan.

\section{Daftar Pustaka}

Badariah, N., Surjasa, D., \& Trinugraha, Y. (2013). Analisa Supply Chain Risk Management Berdasarkan Metode Failure Mode and Effects Analysis ( FMEA ). Jurnal Teknik Industri, $110-118$.

Hadi, J.A., (2019). Identifikasi Risiko Rantai Pasok dengan Metode House of Risk (HOR). Laporan Kerja Praktik. Program Studi Teknik Industri, Universitas Islam Indonesia. Yogyakarta.

Hayati, E. (2015). Supply Chain Management (SCM) dan Logistic Management. Jurnal Ilmiah Dinamika Teknik, 8(1).

Kusnindah, C., Sumantri, Y., \& Yuniarti, R. (2014). Pengelolaan Risiko Pada Supply Chain dengan Menggunakan Metode House of Risk (HOR) (Studi Kasus Di PT XYZ). Jurnal Rekayasa Dan Manajemen Sistem Industri, 2(3), 661-671.

Listyawati, I. H. (2013). Implementasi Relationship Marketing Sebagai Strategi. JBMA, I(2), 2532.

Norken, I. N., Astana, I. N. Y., \& Manuasri, L. K. A. (2012). Manajemen Risiko pada Proyek Konstruksi di Pemerintah Kabupaten Jembrana. Jurnal Ilmiah Teknik Sipil.

Rosih, A. R., Choiri, M., \& Yuniarti, R. (2015). Analisis Risiko Operasional pada Departemen Logistik dengan Menggunakan Metode FMEA. Jurnal Rekayasa dan Manajemen Sistem Industri, 3(3), p580-591.

Shahin, A. 2004. Integration of FMEA and Kano Model: An Exploratory Examination. International Journal of Quality \& Reliability Management, 47(1): 731-746

Tampubolon, F., Bahaudin, A., \& Ferdinant, P. F. (2013). Pengelolaan Risiko Supply Chain dengan Metode House of Risk. Jurnal Teknik Industri, 1(3), 222-226.

Trenggonowati, D. L. (2017). Analisis Penyebab Risiko dan Mitigasi Risiko dengan Menggunakan Metode House of Risk pada Divisi Pengadaan. Journal Industrial Servicess, $3(1), 1-7$.

Widianto, A. (2012). Peran Supply Chain Management dalam Sistem. Manajemen dan Bisnis, 16(2), 91-98. 
[ Halaman kosong ] 